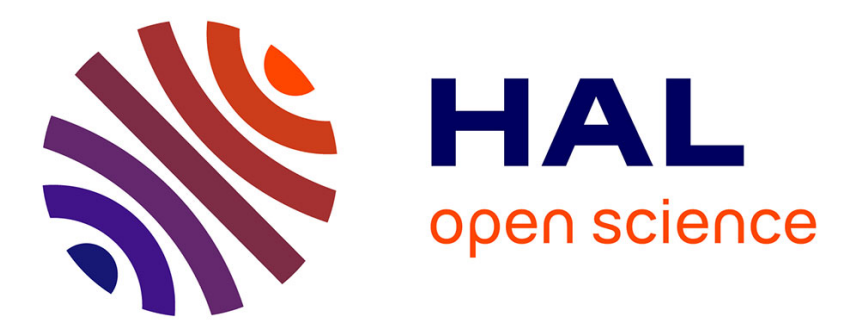

\title{
Identification of strain isolated from dates (Phœnix dactylifera L.) for enhancing very high gravity ethanol production
}

Hayet Djelal, Sofien Chniti, Monia Jemni, Amélie Weill, Walaa Sayed, Abdeltif Amrane

\section{To cite this version:}

Hayet Djelal, Sofien Chniti, Monia Jemni, Amélie Weill, Walaa Sayed, et al.. Identification of strain isolated from dates (Phœenix dactylifera L.) for enhancing very high gravity ethanol production. Environmental Science and Pollution Research, 2017, 24 (11), pp.9886-9894. 10.1007/s11356-016-8018-x . hal-01518038

\section{HAL Id: hal-01518038 \\ https://hal-univ-rennes1.archives-ouvertes.fr/hal-01518038}

Submitted on 8 Jun 2018

HAL is a multi-disciplinary open access archive for the deposit and dissemination of scientific research documents, whether they are published or not. The documents may come from teaching and research institutions in France or abroad, or from public or private research centers.
L'archive ouverte pluridisciplinaire HAL, est destinée au dépôt et à la diffusion de documents scientifiques de niveau recherche, publiés ou non, émanant des établissements d'enseignement et de recherche français ou étrangers, des laboratoires publics ou privés. 
Identification of strain isolated from dates (Phøenix dactylifera L.) for enhancing very high gravity (VHG) ethanol production

Hayet Djelal $^{\mathrm{a}, \mathrm{b} *}$, Sofien Chniti ${ }^{\mathrm{a}, \mathrm{b}, \mathrm{c}}$, Monia Jemni $^{\mathrm{d}}$, Amélie weill ${ }^{\mathrm{e}}$, Walaa Sayed ${ }^{\mathrm{a}}$, Abdeltif Amrane ${ }^{\mathrm{b}}$

${ }^{a}$ Ecole des Métiers de l’Environnement, Campus de Ker Lann, 35170 Bruz, France

bUniversité de Rennes 1, ENSCR, CNRS, UMR 6226, Avenue du Général Leclerc, CS 50837, 35708

Rennes Cedex 7, France

${ }^{c}$ Ecole Supérieure des Industries Alimentaires de Tunis, Université Carthage et sis Avenue de la République, B.P 77, 1054 Amilcar, Tunisie

${ }^{\mathrm{d}}$ Laboratoire de technologies de dattes, Centre Régional de Recherche en Agriculture Oasienne de Degueche, Tozeur, Tunisie

${ }^{\text {e} E Q U A S A ~ C e n t r e ~ d e ~ R e s s o u r c e s ~ e n ~ Q u a l i t e ́ ~ e t ~ S e ́ c u r i t e ́ ~ d a n s ~ l ’ A g r i c u l t u r e ~ e t ~ l e s ~ I n d u s t r i e s ~ A g r o-~}$ alimentaires. Technopôle Brest- Iroise - Parvis Blaise Pascal - 29280 Plouzane, France

*Corresponding author: Tel.: +33 2990588 00; fax: +33 299058809

E-mail address: hayetdjelal@ecole-eme.fr (H. Djelal) 


\begin{abstract}
Ethanol production from by-products of dates in very high gravity was conducted in batch fermentation using two yeasts Saccharomyces cerevisiae and Zygosaccharomyces rouxii, as well as a native strain; an osmophilic strain of bacteria which was isolated for the first time from juice of dates (Phoenix dactylifera L.). The phylogenetic analysis based on the 16S rRNA and gyrB sequence and physiological analysis indicated that the strain identified belongs to the genus of Bacillus, $B$. amyloliquefaciens. The ethanol yields produced from syrup of dates $\left(175 \mathrm{~g} \mathrm{~L}^{-1}\right.$ and $360 \mathrm{~g} \mathrm{~L}^{-1}$ of total sugar) were $40.6 \%$ and $29.5 \%$ respectively. By comparing the ethanol production by the isolated bacteria to that obtained using Z. rouxii and S. cerevisiae, it can be concluded that B. amyloliquefaciens was suitable for ethanol production from syrup of dates and can consume the three types of sugar (glucose, fructose and sucrose). Using Z. rouxii, fructose was preferentially consumed, while glucose was consumed only after fructose depletion. From this, B. amyloliquefaciens was promising for bioethanol industry. In addition, this latter showed a good tolerance for high sugar concentration (36\%), allowing ethanol production in batch fermentation at $\mathrm{pH} 5.0$ and $28^{\circ} \mathrm{C}$ in date syrup medium. Promising yield ethanol produced to sugar consumed were observed for the two osmotolerant microorganisms, Z. rouxii and B. amyloliquefaciens, nearly 32-33\%, which were further improved when they were co-cultivated, leading to an ethanol to glucose yield of $42-43 \%$.
\end{abstract}

Keywords: Bacillus amyloliquefaciens; Saccharomyces cerevisiae; Zygosaccharomyces rouxii; Byproducts of dates; Ethanol; VHG fermentation 


\section{Introduction}

Biomass, or biomass-derived products, is currently considered as one of the most promising options for the use of conventional fossil fuels, due to the foreseeable low cost and abundant resource. The most important advantage of bio-energy is to reduce dependence on non-renewable fossil fuel sources. It can also provide good opportunities to convert renewable organic waste materials into energy. Moreover, Biomass with high sugar content allows to work in fermentation using very high gravity (VHG) conditions. The efficiency of transformation processes are energetically optimized (Laopaiboon et al. 2009; Pereira et al. 2010; Larnaudie et al. 2016).

Exactly, the production of dates is accompanied by a substantial increase of loss during harvest, storage, commercialization and conditioning process. Date by-products, are not consumed because of their low quality (Abbes et al. 2011). Currently, very little use of these by-products is made; they are discarded or used in limited cases for animal feed. Research into date by-products has not been a true reflection of the importance and potential of this crop, since dates are a rich source of certain nutrients and sugars (70-80\%) in the form of glucose, fructose and sucrose (Al-Farsi 2011).

Recently, there has been increased attention in the field of bioenergy as world energy consumption has increased. Ethanol is a renewable energy with high efficiency and low environmental impact. Ethanol production via yeast fermentation may provide an economically competitive source of energy. Among the crucial factors affecting alcoholic fermentation are substrate selection and preparation, microbial selection and adaptation, optimization of fermentation conditions and improvement of fermentation technology (Kasavi et al. 2012).

Saccharomyces cerevisiae is traditionally used for ethanol production- Alfenor et al. (2002) observed that $S$ cerevisiae increased ethanol production in presence of vitamin. A maximum productivity of $0.5 \mathrm{~g}$ $\mathrm{L}^{-1} \mathrm{~h}^{-1}$ was reached in the best fermentation. The aeration strategy is another parameter very determinant for ethanol production with an increase of $25 \%$ of ethanol productivity comparing with micro-aeration, by S cerevisiae (alfenor et al., 2004). Djelal et al. (2006) studied the effect of aeration of ethanol and glycerol production under salt conditions by Hansenula anomala. They well described the effect of oxygen concentration on the bioproduction of both products. More recently, Bideaux et al. (2016) showed that lower was the oxygen/xylose ratio, higher was the ethanol production yield. It should be noted that the performance of $S$ cerevisiae during fermentation was compromised by the impact of variable environmental factors such as hyperosmolarity due to the large amount of sugar (Belloch et al., 2008, Djelal et al., 2012).

Three yeasts (Sacchromyces cerevisiae, Candida pelliculosa and Zygosaccharomyces rouxii) were tested for ethanol production from dates’ syrup. However, performances during fermentation (72 h) were compromised by the impact of the hyperosmolarity due to the large amount of sugars. Only Zygosaccharomyces rouxii can grow under this extreme environmental stress, but it cannot consume glucose and sucrose (Chniti et al. 2014).

It was observed that the strains isolated from a natural substrate gave much better results than those obtained with pure strains. Thus, Abd-Alla et al. (2015) observed that some native strains isolated from agricultural soils cultivated with different plants have high ability to produce biobutanol. A similar study was conducted by Sarris et al. (2009) with a newly isolated Saccharomyces cerevisiae strain for 
the production of ethanol. The authors observed that this strain is performed to convert raw materials into ethanol in high concentration.

This investigation was designed to use an isolated (indigenous) micro-organism from date, by-products өf the Deglet-Nour variety and to evaluate its efficiency for ethanol production in date syrup medium under high initial sugar concentration. In the first part, a comparative study was performed with Saccharomyces cerevisiae 522D and the osmotolerant yeast Zygosaccharomyces rouxii after 150 hours of batch fermentention. In the second part, a study of the kinetics of sugar consumption, ethanol and glycerol production by $Z$. rouxii and $B$. amyliloquifaciens were described. Finally, to improve the ethanol production, a co-culture was conducted with Z. rouxii and the isolated strain.

\section{Materials and methods}

\section{Raw material treatment}

By-products dates “Deglet-Nour”, was procured from Tunisian conditional unit of dates “ALKHALIJ”. The date juice was prepared according to Acourene et al., (2011) and Chniti et al., (2014).

\section{Yeasts strains and inoculum preparation}

The fermentative yeasts Saccharomyces cerevisiae 522D, Zygosaccharomyces rouxii (IP 2021.92) were obtained from the culture collection of the Pasteur Institute (Paris, France). The yeasts strains were maintained in a synthetic medium whose composition (in $\mathrm{g} \mathrm{L}^{-1}$ ) was glucose 20; yeast extract 10; peptone 10 and agar 10 . In all cases, cultures were maintained at $28^{\circ} \mathrm{C}$ for $24 \mathrm{~h}$ and then stored at $4^{\circ} \mathrm{C}$. A given number of drops of a yeast suspension in $\mathrm{KCl} 150 \mathrm{mmol} \mathrm{L}^{-1}$ was grown in $25 \mathrm{~mL}$ of synthtetic medium ( $\mathrm{g} \mathrm{L}^{-1}$ ): glucose, 20; peptone, 10; and yeast extract, 10; in a $0.25 \mathrm{~L}$ bottle on a rotating shaker (New Brunswick, INNOVA 40, NJ, USA) at $180 \mathrm{rpm}, 28^{\circ} \mathrm{C}$ for $18 \mathrm{~h}$. After centrifugation (3000 rpm, $4^{\circ} \mathrm{C}$ and $5 \mathrm{~min}$ ), cells were harvested, re-suspended in $25 \mathrm{~mL} \mathrm{KCl} 150 \mathrm{mmol} \mathrm{L}^{-1}$ and centrifuged again in similar conditions. The suspension obtained after harvesting cells and re-suspending in $10 \mathrm{~mL} \mathrm{KCl}$ $150 \mathrm{mmol} \mathrm{L}^{-1}$ was used to inoculate culture media (Djelal et al., 2005).

\section{Strain isolation from by-products of dates}

A date juice sample was put in fermentation at room temperature for some days until the appearance of ethanol odor. The composition of the tubes of enrichment medium was (in $\mathrm{g} \mathrm{L}^{-1}$ ): yeast extract 4; peptone 5; glucose 25; $\mathrm{KH}_{2} \mathrm{PO}_{4}$ 0.55; $\mathrm{KCl} \mathrm{0.42;} \mathrm{CaCl}_{2}$ 0.12; $\mathrm{FeCl}_{3} 0.0025 ; \mathrm{MnSO}_{4} 0.0025$ and date juice, $50 \mathrm{~mL} \mathrm{~L}{ }^{-1}$. The tubes were seeded by positive culture; then brought to the incubation at $25^{\circ} \mathrm{C}$. Strains were purified by subsequent streaking onto the surface of the Sabouraud chloramphenicol agar (HiMedia Laboratories). The typical colonies were transferred from the solid medium to the broth medium (enrichment medium), then incubated at $25^{\circ} \mathrm{C}$ for $72 \mathrm{~h}$. From the positive tubes (alcoholic fermentation) streaks were made onto the surface of the Wallerstein Laboratory Nutrient medium (WLN; Merck) and the observations were made after 72 hours of incubation at $25^{\circ} \mathrm{C}$ (Pereira-Dias et al. 2000). Only characteristic colonies (green, smooth, curved) were transferred from the WLN agar to 
tubes containing the broth medium. The purification was performed by streaking onto the surface of the Sabouraud chloramphenicol agar.

\section{Identification of the isolated strain}

Identification of the isolated strain was done in EQUASA (Technopole Brest-IROISE, Plouzane, France). 16S rDNA was amplified and sequenced and then a portion of the gene encoding gyrase (gyrB). The sequences were verified using the software BioNumerics and compared to NCBI databases. The phylogenetic tree was realized with the Figtree software.

\section{Biochemical characteristics}

The isolated strain was identified according to their biochemical profiles using the API50 CHB test kit (Biomérieux, Marcy L’Etoile, France).

\section{Date syrup medium preparation for fermentation}

Dates Syrup at $175 \mathrm{~g} \mathrm{~L}^{-1}$ (Medium A) and $360 \mathrm{~g} \mathrm{~L}^{-1}$ (Medium B) of total sugar were supplemented with mineral medium which was well described in Chniti et al. (2014). The total sugar content was expressed in equivalents of glucose (glucose + fructose +1.05 x sucrose) (Guigou et al., 2011). The pH was adjusted to 6.0 using $\mathrm{KOH} 1 \mathrm{~mol} \mathrm{~L}^{-1}$. The medium was transferred into a $500 \mathrm{~mL}$ bottle with a final working volume of $300 \mathrm{~mL}$ and was autoclaved at $120^{\circ} \mathrm{C}$ for $20 \mathrm{~min}$ before adding $\mathrm{NH}_{4} \mathrm{Cl}$ sterilized by filtration on a $0.2 \mu \mathrm{m}$ membrane (Sartorius, Goettingen, Germany). The medium were inoculated with $200 \mu \mathrm{l}$ of yeast or bacterial suspension. Batch fermentation was carried out on an incubator shaker (New Brunswick, INNOVA 40, NJ, USA) at $20 \mathrm{rad} \mathrm{s}^{-1}, 28^{\circ} \mathrm{C}$ for $150 \mathrm{~h}$. All fermentations were performed at least in duplicate.

Dates Syrup at an initial concentration close to $200 \mathrm{~g} \mathrm{~L}^{-1}$ (Medium A) and $360 \mathrm{~g} \mathrm{~L}^{-1}$ (Medium B) of total sugar were supplemented with mineral medium which was well described in Chniti et al. (2014). The total sugar content was expressed in equivalents of glucose (glucose + fructose $+1.05 \mathrm{x}$ sucrose) (Guigou et al., 2011). The $\mathrm{pH}$ was adjusted to 6.0 using $\mathrm{KOH} 1 \mathrm{~mol} \mathrm{~L}^{-1}$. The medium was transferred into a $500 \mathrm{~mL}$ bottle with a final working volume of $300 \mathrm{~mL}$ and was autoclaved at $120^{\circ} \mathrm{C}$ for $20 \mathrm{~min}$ before adding $\mathrm{NH}_{4} \mathrm{Cl}$ sterilized by filtration on a $0.2 \mu \mathrm{m}$ membrane (Sartorius, Goettingen, Germany). The medium were inoculated with $200 \mu$ l of yeast or bacterial suspension. Batch fermentation was carried out on an incubator shaker (New Brunswick, INNOVA 40, NJ, USA) at $20 \mathrm{rad} \mathrm{s}^{-1}, 28^{\circ} \mathrm{C}$ for 150 h. All fermentations were performed at least in duplicate.

\section{Analytical methods}

During the fermentation period a $5.0 \mathrm{~mL}$ sample was taken at several times and centrifuged at 3000 $\mathrm{rpm}, 4^{\circ} \mathrm{C}$ for $5 \mathrm{~min}$. Absorbance at $600 \mathrm{~nm}$ was then measured. The supernatant was used to analyze ethanol, glycerol and residual sugar concentrations with HPLC (Djelal et al., 2005).

The ethanol yield $\left(\mathrm{Y}_{\mathrm{P} / \mathrm{S}}\right)$ was calculated as the actual ethanol produced and expressed as g ethanol per $\mathrm{g}$ total sugar utilized $\left(\mathrm{g} \mathrm{g}^{-1}\right)$. The volumetric ethanol productivity $\left(\mathrm{Q}, \mathrm{g} \mathrm{L}^{-1} \mathrm{~h}^{-1}\right)$ was determined from the 
concentration produced $\left(\mathrm{P}, \mathrm{g} \mathrm{L}^{-1}\right)$ divided by the fermentation time $(\mathrm{t}, \mathrm{h})$ giving the highest ethanol concentration.

\section{Statistical analysis}

Each analysis was done in duplicate and the results were expressed as mean and standard deviation (SD). The Duncan's test was used to compare all mean pairs in conjunction with analysis of variance (ANOVA) using XLSTAT software, version 2013.3.01 (Addinsoft). Differences between means were considered significant when $p<0.05$.

\section{Results and Discussion}

\section{Phylogenetic analysis}

The quality of the sequencing allowed the use of only one of the two sequences obtained. At this stage, it was not possible to confirm the identification of the strain (more than 98\% sequence similarities); it can be either Bacillus subtilis or Bacillus amyloliquefaciens. According to Larsen et al. (2013), a portion of the gene encoding a part of gyrase seems more specific to differentiate these two species.To refine the identification of the strain, a phylogenetic tree based on the analysis of a portion of the gene encoding a part of gyrase (gyrB gene), with strain of $B$. subtilis and B. amyloliquefaciens, was constructed (Fig. 1).

The results of analysis of the sequences suggest that the strain isolated from dates belonged to Bacillus amyloliquefaciens species, possibly subspecies plantarum. The percentage of identification was higher than 98\%. The biochemical test confirmed the identification of the isolated strain as Bacillus amyloliquefaciens species.

Alvindi and Natsuaki (2009) have isolated B. amyloliquefaciens from banana fruit surface, namely able to growth at low water activity, as it is the case in the date syrup. B. amyloliquefaciens strain was also isolated from salt spring in Ovca located in Republic of Serbia, indicating the osmotolerant character of the strain which would explain its adaptation on dry medium such as this of dates (Loncar et al., 2014). Manhar et al. (2015) isolated B. amyloliquefaciens from traditional fermented soybean (Churpi) and observed the high ability of this strain to degrade cellulose. It is well known that Bacillus species have emerged as a robust organism that can grow in extreme environmental conditions and grow easily to very high densities (Kumar et al. 2013).

Comparison of ethanol fermentation by B. amyloliquefaciens, S. cerevisia, Z. rouxii in two culture medium

The production of ethanol was observed for the two yeasts and the isolated bacteria in a culture medium with $175 \mathrm{~g} \mathrm{~L}^{-1}$ (medium A) of sugar content (Table 1); while with a total sugar concentration of $360 \mathrm{~g} \mathrm{~L}^{-1}$ (medium B), the ethanol production was observed only with B. amyloliquefaciens and $Z$. rouxii and no noticeable amount of ethanol was produced by $S$. cerevisiae (Table 1). With $B$. amyloliquefaciens as inoculum strain for the medium A, the maximum ethanol concentration reached 
$89.8 \mathrm{~g} \mathrm{~L}^{-1}$ after $150 \mathrm{~h}$ and it was $73.6 \mathrm{~g} \mathrm{~L}^{-1}$ and $62.6 \mathrm{~g} \mathrm{~L}^{-1}$ for S. cerevisiae and Z. rouxii respectively (Table 1). Among the three tested specie, B. amyloliquefaciens was therefore the most efficient species for ethanol production with near complete sugar consumption (313.56 g L ${ }^{-1}$ total sugar). The yield of ethanol produced per total sugars consumed by the tested strains from date juice is close to those found in the scientific literature, for example: from molasses and olive mill wastewater (Sarris et al., 2014), from food waste hydrolysate (Thongdumyu et al., 2014), from enriched culture medium with vitamin (Alfenore et al., 2012). Given the promising early results, we will study the kinetics of consumption of sugar and ethanol production.

Kinetics of sugar consumption by B. amyloliquefaciens and Z. rouxii

Sugars consumption during culture showed different trends regarding on the one hand the considered sugar and on the other hand the considered yeast. For $200 \mathrm{~g} \mathrm{~L}^{-1}$ of total sugar, a high consumption of glucose and fructose was observed for B. amyloliquefaciens after three days culture (Fig. 2a). Contrarily, the fructose consumption was high for $Z$. rouxii if compared to its consumption of glucose (Fig. 2b); while the consumption of sucrose was observed only for B. amyloliquefaciens.

As shown in Fig. 2a, 2c, all glucose, fructose and sucrose were consumed simultaneously and completely by B. amyloliquefaciens. Sucrose may be hydrolyzed in two ways; in the first and predominant mechanism, sucrose is hydrolyzed by an extacellular invertase. Hydrolysis yields glucose and fructose, which enter into the cell by facilitate diffusion via hexose transporters. In the second mechanism, sucrose can be actively transported in the cells by a proton-symport mechanism and hydrolyzed intracellularly (Stambuk et al., 2000; Batista et al., 2004). More recently, some authors well described why $Z$. rouxii uses firstly fructose in the presence of glucose (Dalkia et al., 2014).

Concerning consumption of sugar by Z. rouxii at high sugars concentration $\left(360 \mathrm{~g} \mathrm{~L}^{-1}\right)$, it should be observed that the assimilation of fructose was observed from the beginning of the culture, while glucose was only used after total consumption of fructose as an energy source for cell maintenance (Fig. 2d).

These results indicate that at high concentrations of reducing sugars, Z. rouxii consumed fructose faster than glucose and sucrose, in agreement with its fructophilic character (Leandro et al. 2011). At high concentration (360 $\mathrm{g} \mathrm{L}^{-1}$ ), fructose significantly inactivated the glucose transporter, preventing the uptake of this sugar. Fructose was able to utilize the glucose transporter, by competing with glucose.

Contrarily and even at very high gravity (VHG) fermentation, B. amyloliquefaciens was able to ferment glucose, fructose and sucrose simultaneously, even if after seven days of culture, sucrose was not completely consumed (Fig. 2c). The isolated strain, which showed the ability to metabolize all sugars present in the culture medium, appears therefore more interesting than the osmophilic yeast Zygosaccharomyces rouxii. 
Kinetics of ethanol production by Bacillus amyloliquefaciens and Zygosaccharomyces rouxii

Both ethanol and glycerol productions were observed for Z. rouxii and B. amyloliquefaciens in the culture media (A) and (B) (Fig. 3). The highest ethanol production was observed for $B$. amyloliquefaciens, 90 and $92 \mathrm{~g} \mathrm{~L}^{-1}$ for culture medium (A) and (B), respectively (Fig. 3a, 3b). It is noteworthy that nearly similar amounts of ethanol were produced during culture in medium A; while and in close connection with sugars consumption (Fig. 2c, 2d), ethanol production by $B$. amyloliquefaciens was significantly higher than the amount produced by Z. rouxii during VHG fermentation (medium B), 92 and $62 \mathrm{~g} \mathrm{~L}^{-1}$ respectively (Figure 3a, 3b). Regarding the osmoprotective metabolite (glycerol), roughly similar amounts were produced by the two species and in both media, (A) and (B) (Fig. 3 c, 3d).

The isolated strain was able to produce ethanol from concentrated date syrup and can consume the three sugars contained in the medium (glucose, fructose and sucrose). Attfield (1997) and JiménezMarti et al. (2011) indicated that, under particular environment, yeasts have to cope with osmotic stress caused by high sugar concentrations; a part of the assimilated sugar is used for cell maintenance to produce glycerol as osmolyte.

The comparison of the ethanol production obtained in this study, using palm date, to those of the literature performed in similar conditions show that the ethanol productivity by the isolated strain gave similar results to those obtained with other strains cultivated on several sources (Table 2). Sarris et al. (2009) observed the possibility of utilizing an industrial grape musts enriched with commercial sugars for high production of ethanol with newly isolated S. cerevisiae strain. It should be noted that in addition to ethanol production, some studies shown the co-production of added-value compounds as glycerol (Djelal et al., 2006), volatile compounds (Sarri et al., 2009) or to mix bioproduction of ethanol with treatment of olive mill wastewater-based media (Sarris et al., 2013).

According to our results, the strain B. amyloliquefaciens isolated from date was promising for the production of ethanol. These results are in agreement with those of Di Pasqua et al. (2014) who showed a high enzymatic activity on lignocellulosic biomass by B. amyloliquefaciens isolated from compost. A microbial mixing gave better ethanol productivity than pure culture of a given strain (Kalyani et al. 2013). Furthermore, the isolation and characterization of novel cellulose hydrolysing enzymes from bacteria are still an active research area, because bacteria have a higher growth rate than fungi, leading to greater production of enzyme (Maki et al. 2009).

Batch fermentation with co-cultures of Bacillus amyloliquefaciens and Zygosaccharomyces rouxii

To check whether the co-culture of indogenous strain (B. amyliloquifaciens) and exogenous strain ( $Z$. rouxii), enhance the production of ethanol from date syrup at $400 \mathrm{~g} \mathrm{~L}^{-1}$ of total sugars, an assay was made in the same conditions as previously described in this study. In view of comparison, pure cultures of each microorganism, B. amyliloquifaciens and $Z$. rouxii were also made. In the figure 4 , the growth of the strains was represented. Before 50 hours of culture, no growth was observed for the indogenous strain, while after this time the cells went up significantly and then leveled off. The growth of the 
exogenous strain did not follow that of B. amyliloquifaciens. Its adaptation required more time than for Z. rouxii. On the other side, the co-culture in the ratio S1/Z.r: $1 / 1$ and S1/Z.r: 1/3 did not affect the growth of $Z$. rouxii. At 150 hours of fermentation, the yield of ethanol production compared to sugar consumed ( $\left.\mathrm{Y}_{\mathrm{EtOH} / \mathrm{s}}\right)$ is quite similar for the two pure cultures. But this yield increased when strains were mixed by $25 \%$ (Fig. 5). The data indicated that the use of B. amyliloquifaciens in co-culture improved the productivity of ethanol by 20\% (Fig. 5). The strain ratio did not affect the results of productivity of ethanol. Of the same, De Bari et al. (2013) observed that the co-cultures of Scheffersomyces stipitis with Saccharomyces cerevisiae ensured faster processes with higher productivity of ethanol than single culture. For instance, Thongdumyu et al. (2014) shown that the fermentation of food waste hydrolysate by co-culture of Zymomonas mobilis and Candida shehatae, shown an increase of ethanol production by $30 \%$ comparative with the single culture (Table 2 ).

The implantation of industrial ethanol production from by-product of dates could be necessary in hot climates and high temperature seasonal deviations. The use of strain acclimated in this conditions will be a definite plus. Developing a non-sterile continuous bioprocess is indisputably necessary for a viable business model. For instance Kopsahelis et al. (2009, 2012) studied an integrated cost effective system for continuous fermentation of non-sterilized molasses during 32 days at $40{ }^{\circ} \mathrm{C}$. They observed no contamination and similar production of ethanol compared to sterilize molasses. Sarris et al. (2014) observed that bioethanol production by S. cerevisiae under non-aseptic conditions from molasses and olive mill wastewater blends did not be affected comparing with aseptic conditions. Thongdumyu et al. (2014) conducted a study of ethanol production from food waste under non-sterile condition and concluded that this raw is an interesting biomass resource for ethanol production. But it is also important to consider the cost of the preparation of the raw material and to take account of different sugars obtained after hydrolysis (Limayen and Ricke, 2012). The cost of enzymatic hydrolysis increased the global cost of the production of ethanol from natural raw material or by-product of the food industry. Thereby the co-culture with fungal as Aspergillus niger and yeast as Saccharomyces cerevisiae appeared an opportunity for the production of enzyme simultaneous with the production of ethanol (Izmirlioglu and Demirci, 2016). It would be therefore more interesting to operate with a microbial consortium for enhancing the ethanol bioproduction from low cost biomass.

\section{Conclusion}

The present study was undertaken to assess the ethanol production from by-products of dates by VHG fermentation process using Saccharomyces cerevisiae, Zygosaccharomyces rouxii and an isolated osmotolerant bacterial strain, which was identified and belonged to "Bacillus amyloliquefaciens". This strain was able to grow in concentrated date juice which presented a very high osmotic pressure, higher than that supported by the conventional yeast $S$. cerevisiae. Under the conditions considered in the present work, B. amyloliquefaciens can consumed the three types of sugars (glucose, fructose and sucrose).These results show the prospect for the use of new isolated bacteria for ethanol production from by-products of dates, or other substrates used for ethanol production. Moreover, $B$. amyloliquefaciens led to high ethanol productivity, 32\% ethanol produced to sugar consumed yield, 
which was further improved when growing in mixed culture with the osmotolerant yeast Z. rouxii, resulting in $42 \% \mathrm{Y}_{\mathrm{EtOH}}$ yield.

\section{References}

Acourene S, Djaafri K, Ammouche A, Amrouche L, Djidda A, Tarma M, Taleb B (2011) Utilization of date wastes as substrate for the production of baker's yeast and citric acid. Biotechnol 10:38-45

Alfenore S, Molina-Jouve C, Guillouet SE, Uribelarrea JL, Goma G, Benbadis L (2002) Improving ethanol production and viability of Saccharomyces cerevisiae by vitamin feeding strategy during fedbatch process. Appl microbial Biotechnol 63:67-72

Alfenore S, Cameleyre X, Benbadis L, Bideaux C, Uribelarrea JL, Goma G, Molina-Jouve C, Guillouet SE (2004) Aeration strategy: a need for very high ethanol performance in Saccharomyces cerevisiae fed-batch process. Appl microbial Biotechnol 63:537-542

Alvindia DG, Natsuaki KT (2009) Biocontrol activities of Bacillus amyloliquefaciens DGA 14 isolated from banana fruit surface against banana crown rot-causing pathogens. Crop Prot 28:236-242

Abbès F, Bouaziz MA, Blecker C, Masmoudi M, Attia H, Besbes S (2011) Date syrup: Effect of hydrolytic enzymes (pectinase/cellulase) on physic-chemical characteristics, sensory and functional properties. LWT- Food Sci Technol 44:1827-183

Abd-Alla MH, Zohri A-N A El-Enany A-W E, Ali SM (2015) Acetone-butanol-ethanol production from substandard and surplus dates by Egyptian native Clostridium strains. Anaerobe 32:27-86

Al-Farsi M, Alasalvar C, Al-Abid M, Al-Shoaily K, Al-Amry M, Al-Rawahy F (2011) Compositional and functional characteristics of dates, syrups, and theirs by-products. Food Chem 104:943-947

Attfield AV (1997) Stress tolerance. The Key to effective strains of industrial baker's yeast. Nat Biotechnol 15:1351-1357

Batista AS, Milleti ASBLC, Stambuk BU (2004) Sucrose fermentation by cerevisiae lacking hexose transport. J Mol Microbiol Biotechnol 8:26-33

Belloch C, Orlic S, Barrio E, Querol A (2008) Fermentative stress adaptation of hybrids within Saccharomyces sensu strico complex. Int J Food Microbiol 122:188-95

Bideaux C, Montheard J, Cameleyre X, Molina-Jouve C, Alfenore S (2016) Metabolic flux analysis model for optimizing xylose conversion into ethanol by the natural C5-fermenting yeast Candida shehatae. Appl Micobiol Biotechnol 100:1489-1499

Chniti S, Djelal H, Hassouna M, Amrane A (2014) Residue of dates from the food industry as a new cheap feedstock for ethanol production. Biomass Bioenerg 69:66-70

Dakal TC, Soliere L, Guidici P (2014) Adaptative response and tolerance to sugar and salt stress in the food yeast Zygosaccharomyces rouxii. Int J of Food Microbiol 185:140-157

De Bari I, De Canio P, Cuna D, Liuzzi F, Capece A, Romano Patrizia (2013) Bioethanol producion from mixed sugars by Scheffersomyces stipitis free and immobilized cells, and co-culture with Saccharomyces cerevisiae. New biotechnol 30 (6):591-597 
Djelal H, Amrane A, Larher F, Martin G (2005) Effect of medium osmolarity on the bioproduction of glycerol and ethanol by Hansenula anamala growing on glucose and ammonium. Appl Microbiol Biotechnol 69:341-349

Djelal H, Larher F, Martin G, Amrane A (2006) Effect of dissolved oxygen on the bioproduction of glycerol and ethanol by Hansenula anomala growing under salt conditions. J Biotechnol 125:95-103

Djelal H, Larher F, Martin G, Amrane A (2012) Impact of an osmotic stress on the intracellular volume of Hansenula anomala, Annals of Microbiology 64 (4), 1345-1352.

Di Pasqua R, Ventorino V, Aliberti A, Robertiello A, Faraco V, Viscardi S, Pepe O (2014) Influence of different lignocelluloses sources on endo-1,4-b-glucanase gene expression and enzymatic activity of Bacillus amyloliquefaciens B31C. BioResources 9 (1):1303-1310

Goncalves FA, Ruiz HA, dos Santos ES, Teixeira JA, de Macedo GR (2016) Bioethanol production by Saccharomyces cerevisiae, Pichia stipitis and zymomonas mobilis from delignified coconut fiber mature and lignin extraction according to biorefinery concept. Renew Energ 94:353-365

Guigou M, Lareo C, Perez LV, Luberas ME (2011) Bioethanol production from sweet sorghum: Evaluation of post-harvest treatments on sugar extraction and fermentation. Biomass Bioenerg 35:3058-3062

Izmirlioglu G, Demirci A (2016) Improved simultaneous saccharification and fermentation of bioethanol from industrial potato waste with co-cultures of Aspergillus niger and Saccharomyces cerevisiae by medium optimization. Fuel 185:684-691

Kalyani D, Lee K-M, Kim T-S, Li Jinglin, Dhiman SS (2013) Microbial consortia for saccharification of woody biomass and ethanol fermentation. Fuel 107:815-822

Kasavi C, Finore I, lama L, Nicolaus B, oliver SG, Oner ET, Kirdar B (2012) Evaluation of industrial saccharomyces cerevisiae strains for ethanol production from biomass. Biomass bioenerg 45:230-238

Kopsahelis N, Nisiotou A, Kourkoutas Y, Panas P, Nychas GJE, Kanellaki M (2009) molecular characterization and molasses fermentation performance of a wild yeast strain operating in an extremely wide temperature range. Bioresour Technol 1001:4854-4862

Kopsahelis N, Bosnea L, Bekatorou A, Tzia C, Kanellaki M (2012) Alcohol production from sterilized and non-sterized molasses by Saccharomyces cerevisiae immobilized on brewer's spent grains in two types of continuous bioreactor systems. Biomass Bioenerg 45:87-94

Kumar P, Patel SKS, Lee JK, Kalia VC (2013) Extending the limits of Bacillus for novel biotechnological applications. Biotechnol Adv 31:1543-1561

Laopaiboon L, Nuanpeng S, Srinophakun P, Klanrit P, Laopaiboon P (2009) Ethanol production from sweet sorghum juice using very high gravity technology: Effects of carbon and nitrogen supplementation. Bioresour Technol 100:4176-4182

Larnaudie V, Rochon E, Ferrari Md, Lareo C (2016) Energy evaluation of fuel bioethanol production from sweet sorghum using very high gravity (VHG) conditions. Renew Energ 88:280-287

Larsen N, Thorsen L, Kpikpi EN, Stuer-Lauridsen B, Cantor MD, Nielsen B, Brockmann E, Derkx PM, Jespersen L (2014) Characterization of Bacillus spp. Strains for use as probiotic additives in pig feed Appl Microbiol Biotechnol 98:1105-1118 
Leandro MJ, Sychrova H, Prista C, Loureiro-Dias MC (2011) The osmotolérant fructophilic yeast Zygosaccharomyces rouxii. Microbiology 157: 601-608.

Letti LAJ, Karp SG, Woiciechowski AL, Soccol CR (2012) Ethanol production from soybean molasses by Zymomonas mobilis. Biomass Bioenerg 44:80-86

Limayen A, Ricke SC (2012) Lignocellulose biomass for bioethanol production: Current perspectives, potential issues and future prospects. Prog Energ Comb Sci 38:449-467

Loncar N, Gligorijevic N, Bozic N, Vujcic Z (2014) Congo red degrading laccases from Bacillus amyloliquefaciens strains isolated from salt spring in Serbia. Int Biodeterior biodegrad 91:18-23

Jiminénez-Marti E, Zuzuarregui A, Gomar-Alba M, Gutierrez D, Gil C, Del-Olmo M (2011) Molécular response of Saccharomyces cerevisiae wine and laboratory strains to high sugar stress conditions. International J Food Microbiol 145: 211-220

Maki M, Leung KT, Qin W (2009) The prospects of cellulose-producing bacteria for the bioconversion of lignocellulosic biomass. Int J Biol Sci 5 (5): 500-516

Manhar AK, Saikia D, Bashir Y, Mech RK, Nath D, Konwar BK, Mandal M (2015) In vitro evaluation of cellulolytic Bacillus amyloliquefaciens AMS1 isolated from traditional fermented soybean (Churpi) as an animal probiotic. Res Vet Sci 99:149-156

Pereira FB, Guimaraes PMR, Teixeira JA, Domingues L (2010) Optimisation of low-cost medium for very high gravity ethanol fermentations by Saccharomyces cerevisiae using statistical experimental designs. Bioresour Technol 101:7856-7863

Pereira-Dias S, Potes ME, Marinho A, Malfeito-Ferreira M, Loureiro V (2000) Characterisation of yeast flora isolated from an artisanal Portuguese ewes’ M.cheese. Int J Food Microbiol 60:55-63

Sarris D, Kotseridis Y, Linga M, Galiotou-Panayotou M, Papanikolaou S (2009) Enhanced ethanol production, volatile compound biosynthesis and fungicide removal during growth of a newly isolated Saccharomyces cerevisiae strain on enriched pasteurized grape musts. Eng Life Sci 9 (1):29-37

Sarris D, Giannakis M, Philippoussis A, Komaitis M, Koutinas AA, Papanikolaou S (2013) Conversion of olive mill wastewater-based media by saccharomyces cerevisiae through sterile and non-sterile bioprocesses. J Chem Technol Biotechnol 88:958-969

Sarris D, Matsakas L, Aggelis G, Koutinas AA, papanikolaou S (2014) Aerated vs non-aerated conversion of molasses and olive mill wastewaters blend into bioethanol by saccharomyces cerevisiae under non-aseptic conditions. Ind Crops Prod 56:83-93

Stambuk BU, Batista AS, De Arauyo PS (2000) Kinetic of active sucrose transport in Saccharomyces cerevisiae. J Biosci Bioeng 89: 212-214

Thongdumyu P, Intrasungkha N, O-Thong S (2014) Optimization of ethanol production from food waste hydrolysate by co-culture of Zymomonas mobilis and Candida shehatae under non sterile condition. Afr J Biotechnol 13 (7):866-873 


\section{Figure captions}

Fig. 1 Phylogenetic tree of members of the genus Bacillus, based on gyrB gene sequences

Fig. 2 Sugars consumption by B. amyloliquefaciens (a), $175 \mathrm{~g} \mathrm{~L}^{-1}$, (c), $360 \mathrm{~g} \mathrm{~L}^{-1}$ and Z. rouxii (b) $175 \mathrm{~g}$ $\mathrm{L}^{-1}$, (d) $360 \mathrm{~g} \mathrm{~L}^{-1}$

Fig. 3 Ethanol and glycerol productions (a) and (c) at $175 \mathrm{~g} \mathrm{~L}^{-1}$ and (b) et (d) at $360 \mathrm{~g} \mathrm{~L}^{-1}$ by $B$. amyloliquefaciens (S1) and Z. rouxii (Z.r)

Fig. 4 Growth of B. amyliloquifaciens (S1), Z. rouxii (Z.r), and their co-culture in the ratio S1/Z.r: 1/1 and S1/Z.r: 1/3 from date syrup with an initial concentration of $400 \mathrm{~g} \mathrm{~L}^{-1}$ of total sugars

Fig. 5 Comparison of ethanol production yield (grey bars) and ethanol productivity (white bars) during single cultures of B. amyliloquifaciens (S1), Z. rouxii (Z.r), and their co-culture in the ratio S1/Z.r: 1/1 and S1/Z.r: 1/3 from date syrup with an initial concentration of $400 \mathrm{~g} \mathrm{~L}^{-1}$ of total sugars at 150 hours of culture 
Fig. 1

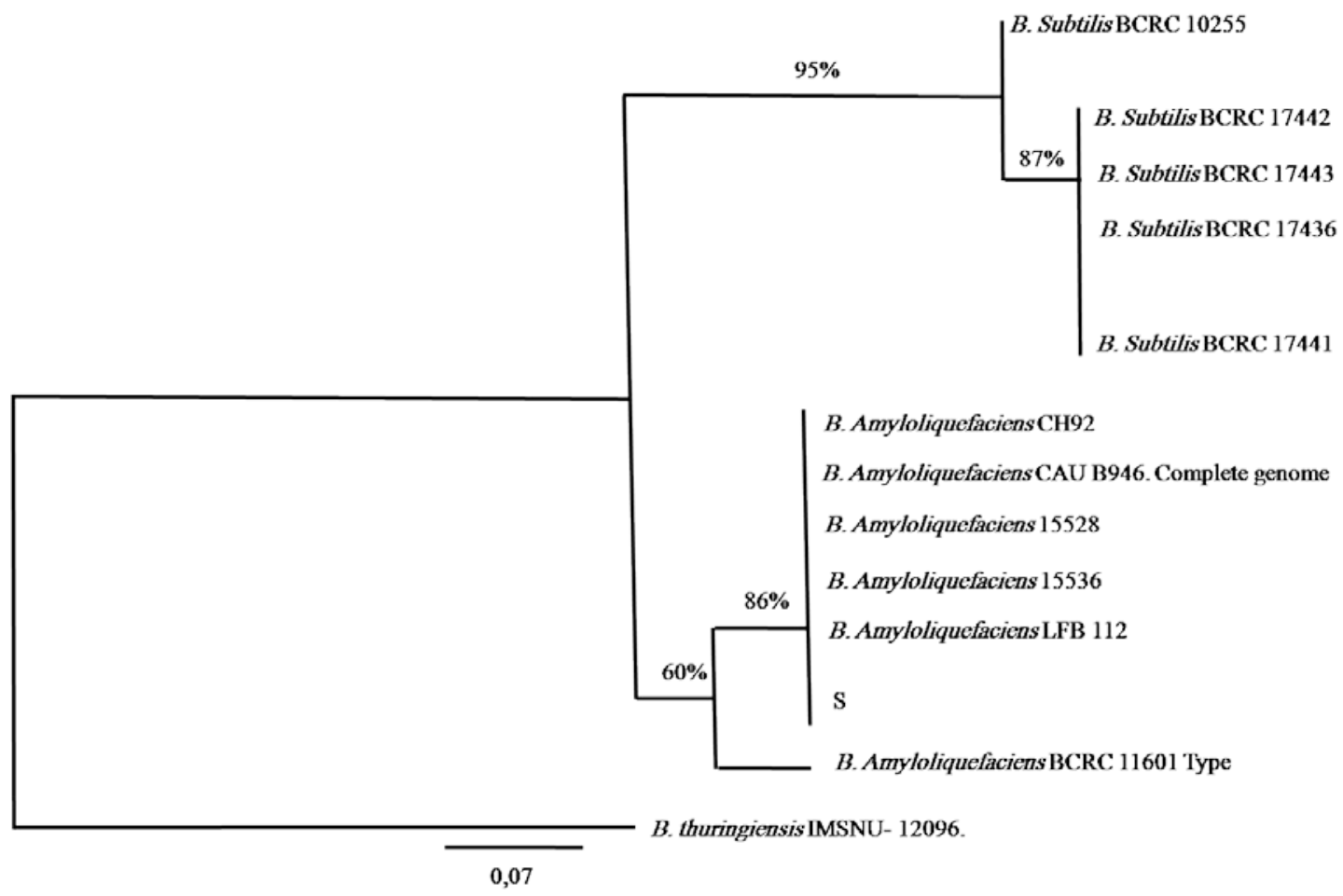


Fig. 2

Fig. 3
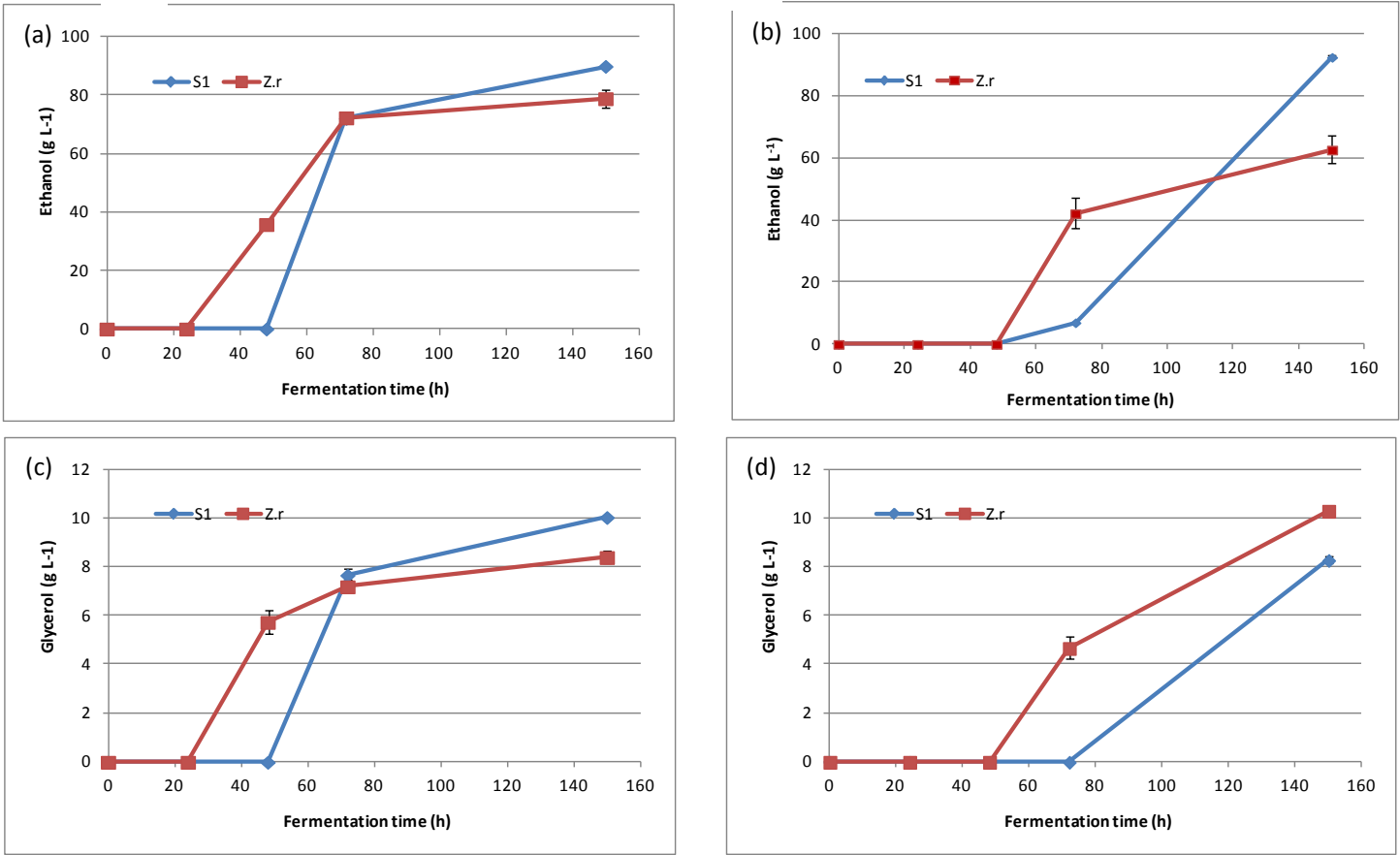
Fig. 4

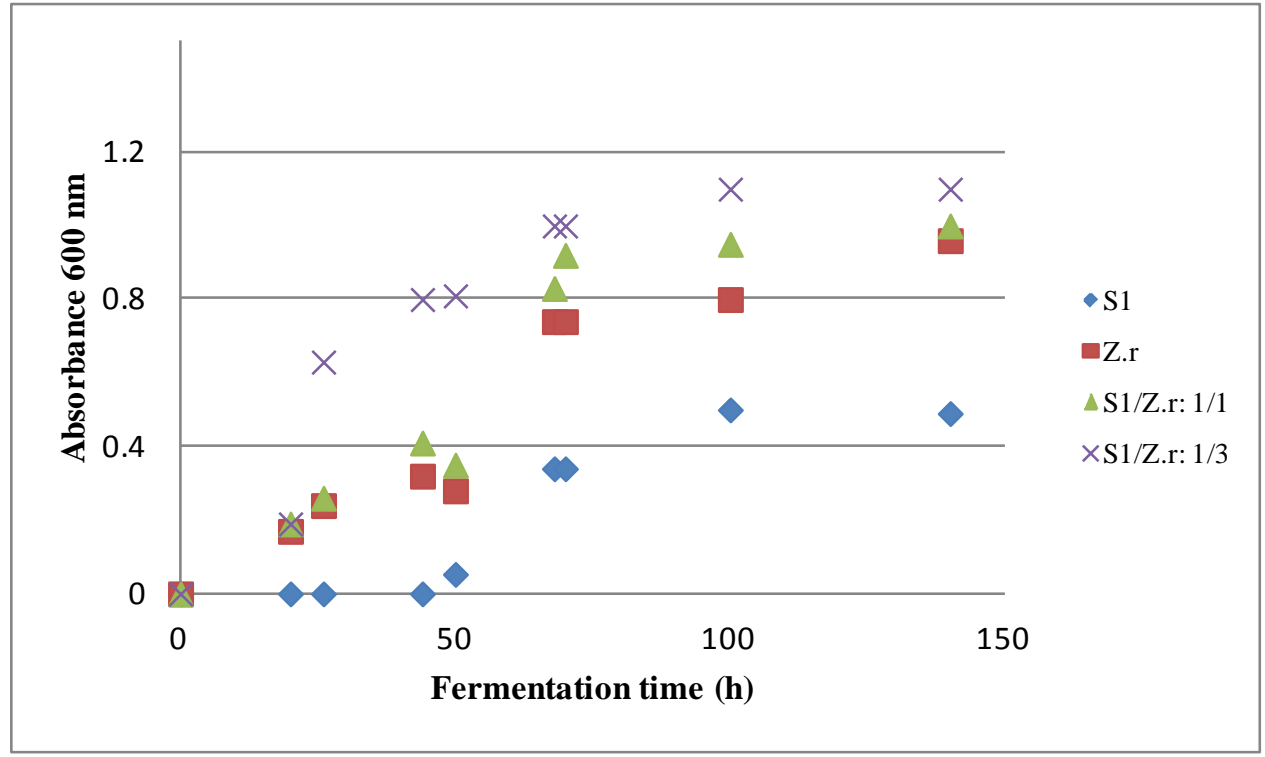


Fig. 5

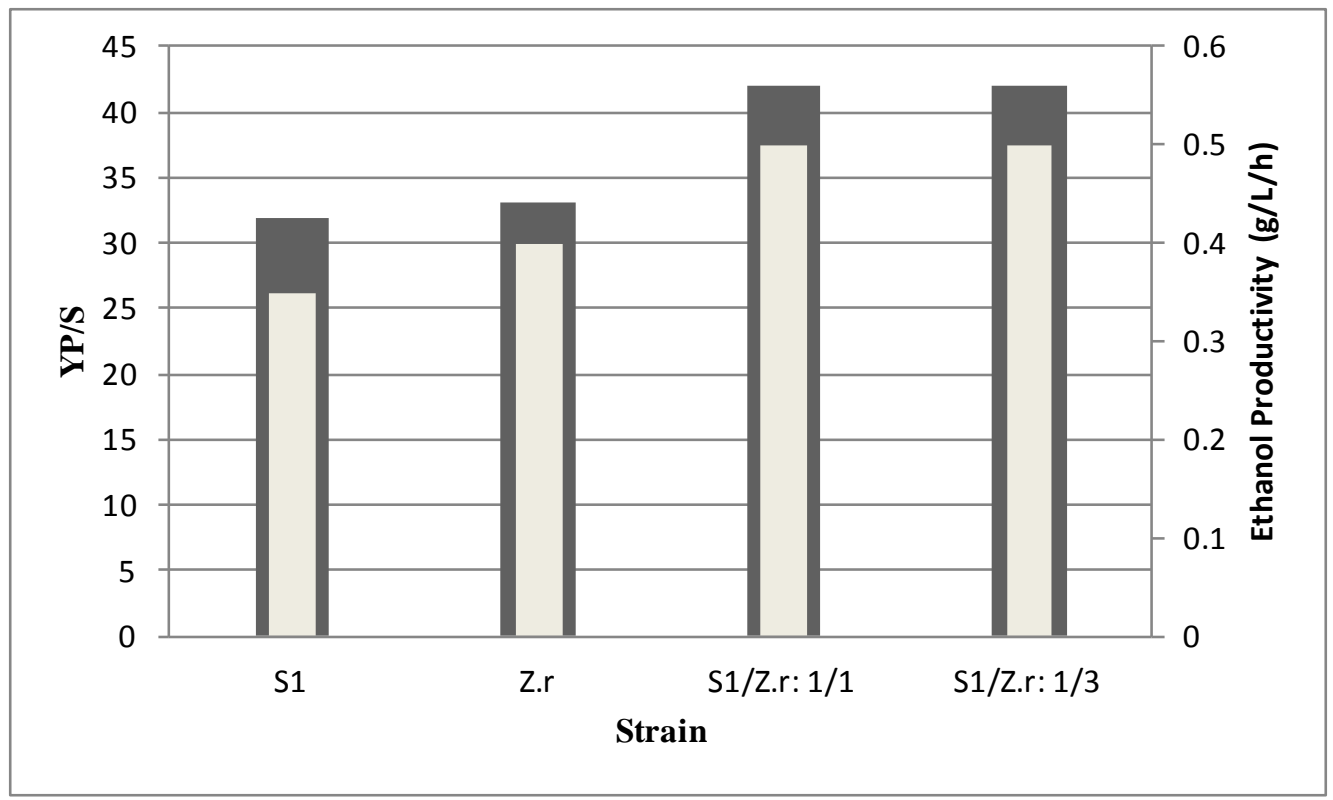

